Research Article

\title{
Transcriptional and Epigenetic Bioinformatic Analysis of Claudin-9 Regulation in Gastric Cancer
}

\author{
Elizabeth Hernández-Nava ${ }^{(D)}$, Luis F. Montaño $(D)$, and Erika P. Rendón-Huerta \\ Laboratorio Inmunobiología, Departamento Biología Celular y Tisular, Facultad de Medicina, UNAM, Mexico City, Mexico \\ Correspondence should be addressed to Erika P. Rendón-Huerta; erendon@unam.mx
}

Received 13 September 2021; Revised 15 November 2021; Accepted 30 November 2021; Published 18 December 2021

Academic Editor: Yuan Seng Wu

Copyright (c) 2021 Elizabeth Hernández-Nava et al. This is an open access article distributed under the Creative Commons Attribution License, which permits unrestricted use, distribution, and reproduction in any medium, provided the original work is properly cited.

\begin{abstract}
Gastric cancer is a heterogeneous disease that represents 5\% to $10 \%$ of all new cancer cases worldwide. Advances in histological diagnosis and the discovery of new genes have admitted new genomic classifications. Nevertheless, the bioinformatic analysis of gastric cancer databases has favored the detection of specific differentially expressed genes with biological significance. Claudins, a family of proteins involved in tight junction physiology, have emerged as the key regulators of cellular processes, such as growth, proliferation, and migration, associated with cancer progression. The expression of Claudin-9 in the gastric cancer tissue has been linked to poor prognosis, however, its transcriptional and epigenetic regulations demand a more comprehensive analysis. Using the neural network promoter prediction, TransFact, Uniprot-KB, Expasy-SOPMA, protein data bank, proteomics DB, Interpro, BioGRID, String, and the FASTA protein sequence databases and software, we found the following: (1) the promoter sequence has an unconventional structure, including different transcriptional regulation elements distributed throughout it, (2) GATA 4, GATA 6, and KLF5 are the key regulators of Claudin-9 expression, (3) Oct1, NF- $\kappa$ B, AP-1, c-Ets-1, and HNF- $3 \beta$ have the higher binding affinity to the CLDN9 promoter, (4) Claudin-9 interacts with cell differentiation and development proteins, (5) CLDN9 is highly methylated, and (6) Claudin-9 expression is associated with poor survival. In conclusion, Claudin-9 is a protein that should be considered a diagnostic marker as its gene promoter region binds to the transcription factors associated with the deregulation of cell control, enhanced cell proliferation, and metastasis.
\end{abstract}

\section{Introduction}

Gastric cancer is the third leading cause of cancer-related deaths worldwide [1]. There are two main subtypes of gastric cancer, namely intestinal and diffuse. The intestinal type is associated with $H$. pylori infection, whereas the diffuse type is mainly hereditary and possesses multiple mutations $[2,3]$. In the study of gastric cancer, epigenetics has been thought of as a critical factor in developing new strategies for the understanding of molecular processes [4]. The changes in the profile gene expression are the fundamental properties of aggressiveness and good tools in the prognosis of several oncological diseases [5]. New genes in the genomic context are attracting attention by playing essential roles in the progression of the disease [6].

The tight junctions (TJs) are intercellular adhesion complexes located in the apical zone of the lateral membrane of the epithelial and endothelial cells. TJs are essential for barrier function and cell polarity by limiting the movement of the proteins within the plasma membrane and regulating the paracellular solute [7]. TJs are made up of adapter proteins and integral membrane proteins, such as claudins, which are indispensable for TJ strand formation [8]. Claudins, a family of 27 isoforms, which, in addition to having barrier and polarity functions, also function as coreceptors for viruses and bacterial toxins, are coexpressed in specific cell types and are functionally divided into four groups with different functions [9]. The transcription of claudins is tightly controlled by regulatory mechanisms, epigenetic alterations, transcriptional changes, and posttranslational modifications [10]. Nevertheless, the understanding of the structure and function of $\mathrm{TJ}$ has been amplified as the appearance of chimeric claudins [11]. The repercussion of other components, such as junctional 
adhesion molecules, zonula occludens proteins, membrane lipids, and mechanical forces, have transformed our knowledge of the structure, dynamic interaction, and function of TJ assembly [12]. Interestingly, the functional crosstalk between $\mathrm{TJ}$ proteins and signaling pathways involved in cell proliferation, transformation, and metastasis is becoming a current topic [13].

Claudins play a crucial role in regulating cellular processes such as growth, proliferation, and migration $[14,15]$. The disruption of cell-cell junctions results in the loss of cell polarity and has a decisive role in cancer progression [16]. Claudin expression is altered, elevated, and negatively regulated in cancer, but most intriguingly, claudin expression is tumor-specific [17]. Bioinformatics analysis has extensively confirmed the prevalence of claudins in gastric cancer patients [18-22], especially Claudin -6 and -9 , which are considered critical factors related to poor prognosis in gastric cancer [23, 24]. Claudin-9 is expressed primarily in the inner ear and is essential for hearing [25], however, its aberrant expression has been reportedly established in lung cancer [26], pituitary oncocytoma [27], and cervical carcinoma [28]. Claudin-9 has been included in a seven-gene signature as a clinical prognosis marker in esophageal adenocarcinoma [29]. Despite the above, there is a limited body of literature that recognizes the significance of Claudin-9 in gastric cancer.

The increase in Claudin-9 expression in the gastric cancer tumor tissue is associated with an increase in cell proliferation and invasion. Furthermore, Claudin- 9 overexpression is associated with a higher mortality rate $(66 \%)$ in diffuse-type gastric cancer $[30,31]$. The present work aimed to perform a bioinformatics analysis to understand the mechanisms involved in the transcriptional and epigenetic regulation of Claudin-9 and its repercussions in gastric cancer.

\section{Material and Methods}

2.1. Claudin 9(CLDN9) Datasets. CLDN9 gene sequence was obtained from National Center for Biotechnology Information (NCBI, https://www.ncbi.nlm.nih.gov/) (Gene ID: 9080), and a blast was performed to obtain the reference number and the sequence in FASTA format. Subsequently, the Genome Browser database (https://genome.ucsc.edu/) was used to analyze the genomic context of the CLDN9 gene. In the sequence section, upstream of the $5^{\prime}$ end was adjusted to $2500 \mathrm{bp}$ for further promoter analysis.

2.2. Data Processing. Firstly, we look to determine the minimum promoter region using "neural network promoter prediction." In addition, we evaluated the presence of consensus regulatory sequences, such as CpG islands, TATA, CAAT and GC boxes, GATA, Inr (Initiator), and DPE (downstream promoter element) sequences.

2.3. Prediction of Transcription Factors. TRANScription FACtor database (TRANSFACT; http://gene-regulation. com) was used to identify possible transcription factors and their binding sites in the CLDN9 gene promoter. TRANSFACT uses two algorithms. The first describes the binding sites in the promoters or enhancers, and the second shows the transcription factors. Again, using a $2500 \mathrm{bp}$ sequence upstream of the transcriptional start site of CLDN9, we perform the analysis. The search settings were established in the match: vertebrates, minimize the sum of both errors pattern: 0.7-0.75 cut-off-best selection-prf. A similarity of $100 \%$ was considered for further analysis of molecular docking with their corresponding promoter sequence.

We use the Signaling Pathway Project experimental database (https://www.signalingpathways.org/index.jsf), to study the possible transcription factors. The "Ominer" tool (https://www.signalingpathways.org/ominer/query.jsf) was used to discover the relationship between the single gene CLDN9 and the node of transcription factors using cistromics datasets (Chip-Seq) in the bio sample category of human in the stomach tissue.

2.4. Molecular Docking Analyses. Crystal availability and biological relevance in the cancer context were considered for factor selection and molecular docking analysis. The crystallographic structures were obtained from the Protein Data Bank (http://www.rcsb.org/pdb). The Homo sapiens crystals used were OCT-1 (1E3O; 280-438 aa), NF-kappaB (1SVC; 2-365 aa), AP-1 (1JNM; 254-315 aa), C-ets-1 (1GVJ; 297-441 aa), and HNF-3 $\beta$ (5X07; 157-258 aa). Three-dimensional DNA models were built using "The Supercomputing Facility for Bioinformatics \& Computational Biology," IIT Delhi (SCFBio, http://www.scfbio-iitd.res.in/). Docking studies were calculated using different configurations of the HDOCK server (http://hdock.phys.hust.edu.cn/ ). Finally, the visualization of the molecular models was done using Chimera software ver. 1.11.2.

2.5. Methylation Bioinformatic Analyses. Disease meth version 2.0 database (http://bio-bigdata.hrbmu.edu.cn/ diseasemeth/) concentrates the aberrant methylomes of different types of cancer. Methylation was analyzed from the Cancer Genome Atlas (TCGA) Gastric Cancer Patient Data Repository (STAD). The data were obtained using the Illumina Infinitum HumanMethylation 450 Beadchip technology experimental platform $(n=397)$. The differential analysis method was Student's $t$-test. $P=0.05$ was considered a significant value. The absolute methylation difference was set at $>0.2$. The methylation analysis of the promoter region $(2 \mathrm{kB}$ upstream to TSS to $0.5 \mathrm{kB}$ downstream) of CLDN9 was performed using the MethBrowser tool.

Xena server (https://xena.ucsc.edu/) was used to explore the possible associations of the CLDN9 promoter methylation with its expression levels and differential methylation between the histological types. Likewise, the impact of CLDN9 methylation on different clinical consequences, such as overall survival (OS), progression-free interval (PFI), and the disease-free interval was analyzed. 
2.6. Structural Characteristic Analyses. For the study of the structure, sequence, and domains of CLDN9, the polypeptide sequence was obtained using the databases Uniprot-KB (https://www.uniprot.org/), secondary structure prediction was determined using Expasy-SOPMA software (https:// npsa-prabi.ibcp.fr/cgi-bin/npsa_automat.pl?page=/NPSA/ npsa_sopma.html), protein data bank (https://www.rcsb. org/), proteomics DB (https://www.proteomicsdb.org/), and Interpro (https://www.ebi.ac.uk/interpro/). The FASTA protein sequence was used for all analyses. We chose the 095484 entries in UniprotKB, CLDN9_HUMAN entry name, Homo sapiens organism.

In the case of Expasy-SOPMA, we used UNK_645620 ID protein for Claudin-9 [32].

Pharos was used to analyze the data compiled in a knowledge management base taking into account the complexity of the analyzed targets. With this tool, it was sought to efficiently visualize and summarize the results to identify the patterns. The information reviewed and related to Claudin- 9 was tissue and cell type, cell component, disease disturbance, genetic alterations, metabolism, molecular function, protein domains, PubMedID, SNP, and transcription factors, among others.

2.7. Protein-Protein Interactions Networks. The general interaction map of Claudin-9 was generated using the String database (https://string-db.org/cgi/input?sessionId=biUPD H3R9Of4\&input) to analyze known interactions (from curated databases and experimentally determined), predicted interactions (gene neighborhood, gene fusions, and gene co-occurrence), and others (textmining, coexpression, and protein homology). In String, the lines denote the physical or theoretical interactions, and the ends of each line denote the effect on the protein. In this case, the circle at the end of the line indicates that the result is unknown. The analysis of interaction was performed using confidence fields. The thicker the line and the closer they are to each other, the greater the interaction confidence. Additionally, we used BioGRID (https://thebiogrid.org/) to investigate the physical interaction with Claudin-9. The settings used for the assays in both databases were CLDN9; primary external reference: UniProt O95484; species: Homo sapiens; Identifier: R-HSA-421271.

2.8. Expression and Survival Analyses. The clinical impact was evaluated using the Xena Functional Genomics Browser (https://xenabrowser.net/). In addition, data from 580 samples from the TCGA Stomach Cancer Study (STAD) were used to analyze the impact of Claudin- 9 expression in gastric cancer patients.

For the analysis of Claudin-9 expression in the different histological types of gastric cancer (TCGA STAD study), we compared the histologic type and the gene expression by RNAseq-IlluminaHiSeq UNC for the CLDN9 gene. The statistical test to determine the differences in the expression of Claudin-9 in the histological types was one-way ANOVA.

The overall survival (OS) and progression-free interval (PFI) of the patients and their association with the expression of the CLDN9 gene generated by RNAseq-IlluminaHiSeq UNC were analyzed. For OS, the samples were divided into low- $(<3,679)(n=222)$ and high- $(\geq 3,679)(n=221)$ CLDN9 expression. For the case of PFI, the samples were divided into low- $(<3,679)(n=223)$ and high- $(\geq 3,679)(n=222)$ CLDN9 expression. All survival analyses were performed and analyzed using the Kaplan Meier plots.

\section{Results}

3.1. Prediction of Transcriptional Regulatory Elements and Promoter of CLDN9. The features of the CLDN9 gene promoter $2500 \mathrm{bp}$ upstream of the transcription start point were screened. As shown in Figure 1(a), the promoter sequence has an unconventional structure as different transcriptional regulation elements are distributed throughout the $2500 \mathrm{bp}$. The Neural Network Promoter Prediction software analysis identified two sequences that interact with the GATA factors and GC and CAAT boxes. According to the conventional definition, one GATA binding sequence, two GC boxes, and the initiating region integrated a minimal promoter region. The transcription start point was located between -965 and $-915 \mathrm{bp}$. A distal promoter was also detected between -2450 and $-1635 \mathrm{bp}$. Three CAAT boxes integrated this promoter and one GATA binding sequence, with the transcription start point located between -2071 and -2021 bp (Figure 1(b)).

3.2. Transcription Factors. Twenty-two transcription factors were predicted by TRANSFACT to exist within the transcription start point and $2500 \mathrm{bp}$ upstream (Table 1). The score of all of them is $100 \%$, thus implying a high possibility of binding with the promoter sequence. Interestingly, most of them are strongly related to cancer initiation and progression.

The analysis performed in the Signaling Pathway Project showed GATA6 and GATA4 as the regulators of CLDN9 expression in the YCC3 and AGS epithelial cell lines, respectively, whereas KLF5 was the regulator in KATO III cells (Figures 2(a) and 2(b)).

3.3. Molecular Docking Analysis. Anchorage analysis was performed to predict the binding affinity of c-Ets-1, NF- $\kappa$ B, HNF- $3 \beta$, Oct1, and AP- 1 to the CLDN9 promoter. The docking scores obtained were -377 for Octl, -312 for NF- $\kappa \mathrm{B},-276$ for AP-1, -261 for c-Ets-1, and -266 for HNF-3 $\beta$ (Figure 3). All distances between the interacting residues were $<4 \AA$.

3.4. Epigenetic Regulation Analysis. A comparison with the normal controls showed an increasing trend of methylation in the stomach cancer samples (Disease meth v. 2.0 STAD database). Therefore, a more exhaustive bioinformatics analysis of the promoter region was performed using the data from the cancer genome atlas.

Because of the closeness in the genomic context and their functional similarities, a comparison of the promoter's methylation between the CLDN9 and CLDN6 genes was 


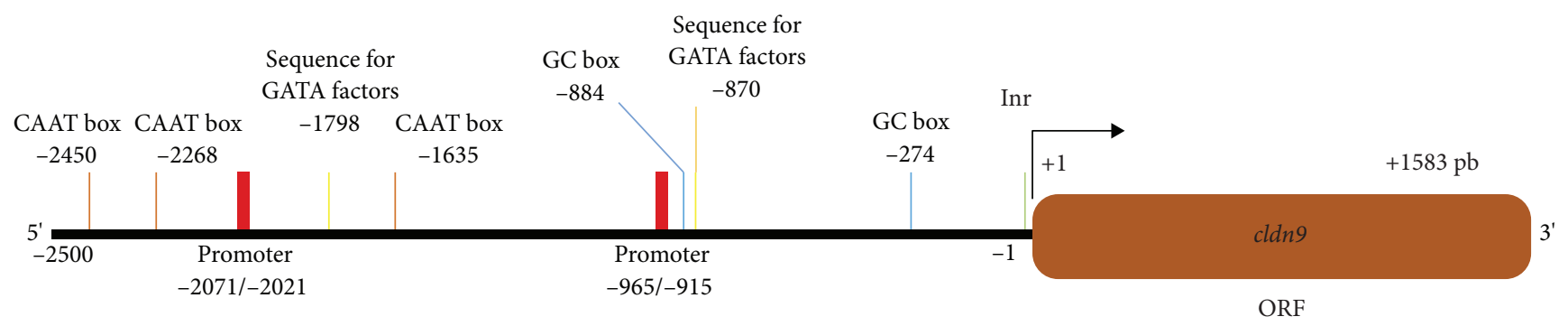

(a)

5

TGCCTGGGCCTTAAAACCCCGCCTGCAGCCGAGAGCCCGCAGAGTCCCC A $3{ }^{\prime}$

5'AACCCTCCCCCACAAATGAGGGGCACATGTTTGTGGGTGCATGTTCTGTG 3'

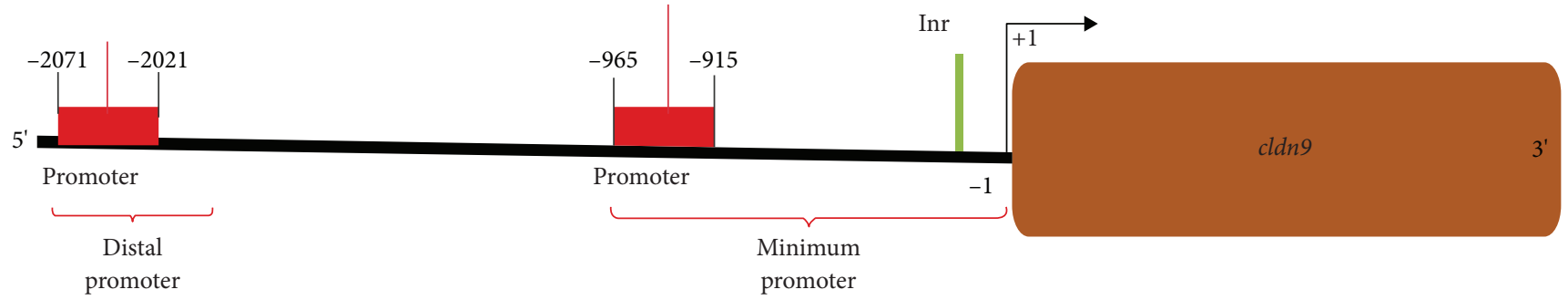

(b)

Figure 1: CLDN9 gene promoter region. (a) Elements of transcription regulation of the region $2.5 \mathrm{kB}$ upstream $\left(5^{\prime}\right)$ to TSS to $0.5 \mathrm{kB}$ downstream $\left(3^{\prime}\right)$. (b) Distal (score 1.00) and Minimun (score 0.89) promoter regions determined by Neural Network Promoter Prediction software.

TABLE 1: Transcription factors.

\begin{tabular}{lccc}
\hline $\begin{array}{l}\text { Transcription } \\
\text { factors }\end{array}$ & Score & $\begin{array}{c}\text { Strand } \\
\text { position }\end{array}$ & Sequence \\
\hline ZID & 100 & $61(+)$ & gGGCTCcagcaca \\
CP2 & 100 & $69(+)$ & gcacacCCCAG \\
c-Ets-1 & 100 & $284(-)$ & tgccTCCGGT \\
Nkx2-5 & 100 & $464(+)$ & tcAAGTG \\
Elk-1 & 100 & $602(-)$ & aaccTTCCGattta \\
USF & 100 & $714(-)$ & acctCGTGAa \\
MyoD & 100 & $771(-)$ & ccgcACCTgcc \\
AREB6 & 100 & $771(+)$ & ccgcACCTgcc \\
SOX-9 & 100 & $799(+)$ & agacaACAATcctc \\
Sox-5 & 100 & $801(+)$ & acaACAATcc \\
HNF-4 & 100 & $924(-)$ & agtgggtCTTTGaccaaag \\
c-Rel & 100 & $1055(+)$ & gggttTTTCC \\
GATA-3 & 100 & $1318(+)$ & ggaGATCTta \\
v-Myb & 100 & $1412(-)$ & ggCCGTTgcc \\
RFX1 & 100 & $1414(-)$ & ccGTTGCcagggcgatgc \\
NF-kB & 100 & $1479(+)$ & cgGGGACcttcccc \\
HNF-3 $\beta$ & 100 & $1586(+)$ & gggcaTGTTTgcatc \\
Oct-1 & 100 & $1589(-)$ & catgTTTGCatcacg \\
AP-4 & 100 & $1624(+)$ & agaggCAGCTggggaggg \\
GATA-1 & 100 & $1919(-)$ & tcccTATCCcggc \\
E47 & 100 & $2082(+)$ & cagtgcgTCTGGaggg \\
AP-1 & 100 & $2391(+)$ & ctgAGTCAc \\
\hline
\end{tabular}

performed. Cadherin 1 gene, a gene regulated by methylation in the gastric tissue, was added as a control. The CLDN9 gene was highly methylated in contrast to CLDN6, which showed lower levels (Figures 4(a) and 4(b)). The methylation of CDH1 was significantly lower (Figure 4(c)). The heat map results of claudin gene methylation showed transcriptional repression of the CLDN9 gene expression in gastric cancer patients (Figure 4(d)).

High- and low-risk values for the CLDN9 gene were calculated according to the median value of gene methylation. There were no significant differences in overall survival between high- and low-methylation groups $(P=0.6871)$ (Figure 4(e)). Similarly, the group with the highest methylation remained disease-free slightly longer without disease recurrence than the group with the lowest methylation $(P=0.7238)$ (Figure $4(f))$. The progression-free interval was slightly better but not significant in the lower methylation group $(P=0.1249)$ (Figure $4(\mathrm{~g}))$.

3.5. Secondary Structure of Claudin-9. The CLDN9 gene codifies an RNA that translates a protein with 217 amino acids of $22.8 \mathrm{kDa}$. The predicted secondary structure of Claudin-9 using the SOPMA method identified $\alpha$-helixes (50.69\% of the sequence), extended strands ( $13.36 \%$ of the sequence), $\beta$-turns (5.07\% of the sequence), and random coils $(30.88 \%$ of the sequence) (Figure 5(a)). Interpro databases were used to identify nonconserved (blue) and nonintegrated (brown and pistachio green) elements within the protein. The most representative figure is the secondary structure prediction in which the transmembrane $\alpha$-helix (blue, spiral structure), sheet (red, folding), turn (green), and coil (purple) generate an irregular curly structure (Figure 5(a)).

The sequence alignment results showed that Claudin-9 is highly similar to Claudin-6 and -8 as they possess 217 to 220 residues compared to Claudin-18 that has 261 residues. The analysis showed that there are regions present in Claudin-18 $(148-159,234-258)$ that are not in Claudin-6, -8, and -9. 


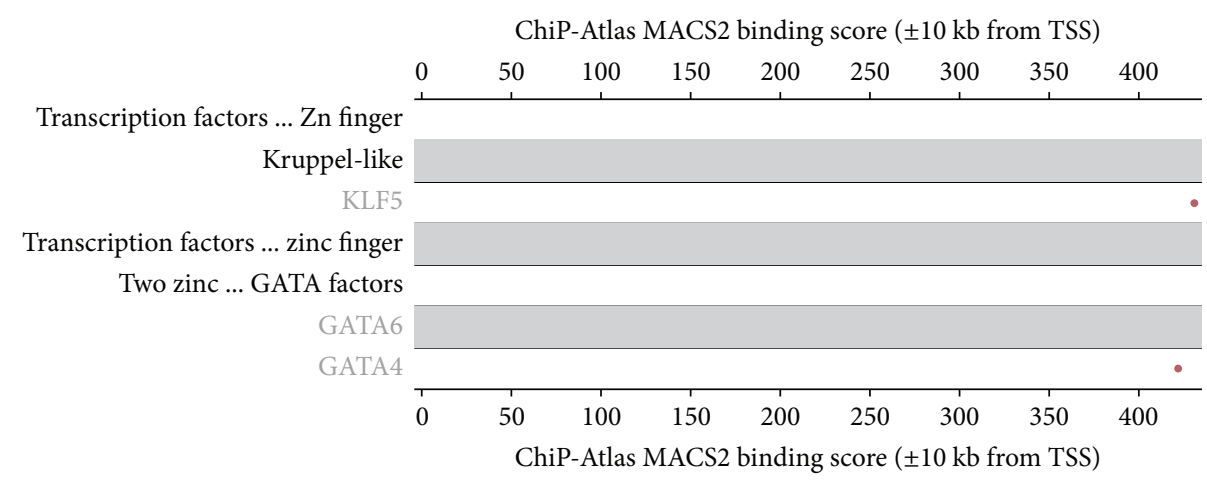

(a)

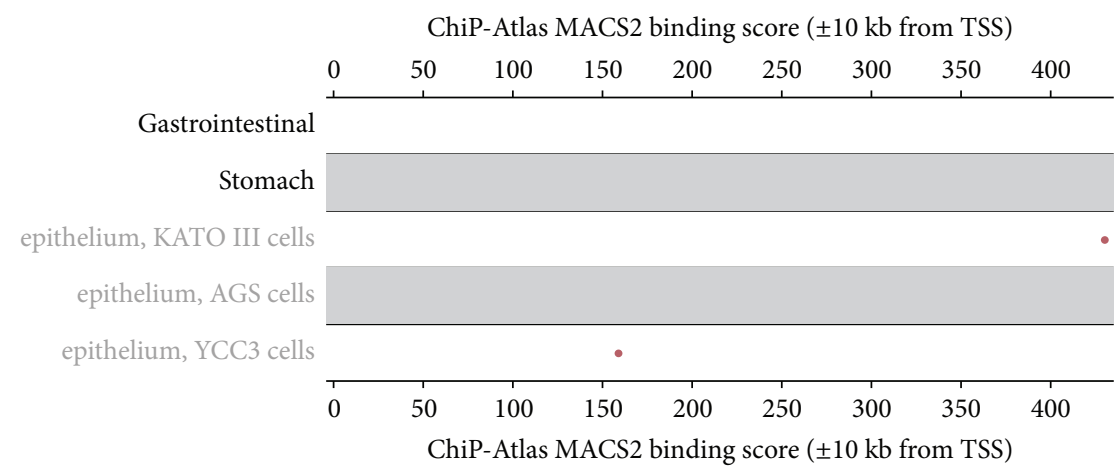

(b)

FIgURE 2: Transcription factors bound to the CLDN9 promoter region. (a) Binding score of transcription factors bound to the CLDN9 promoter region determined by ChiP assays (ChiP-Atlas MACS2) obtained from the Signaling Pathway Project. (b) Cell lines used to determine the transcription factors involved in the regulation of cldn 9 gene.

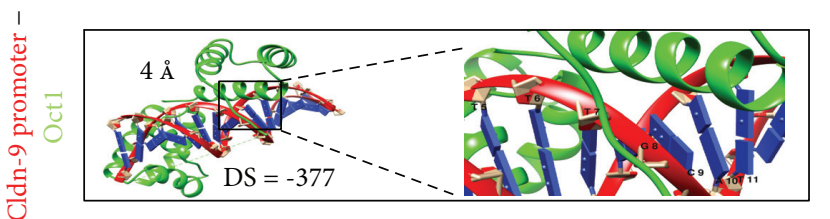

(a)

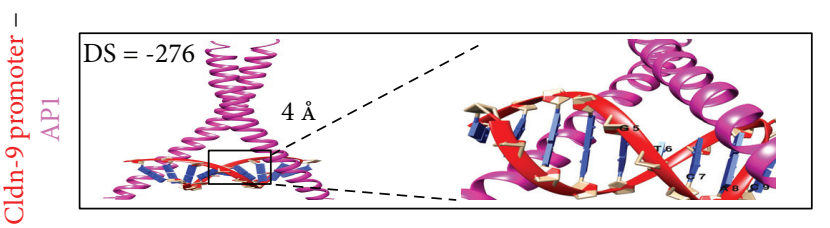

(c)

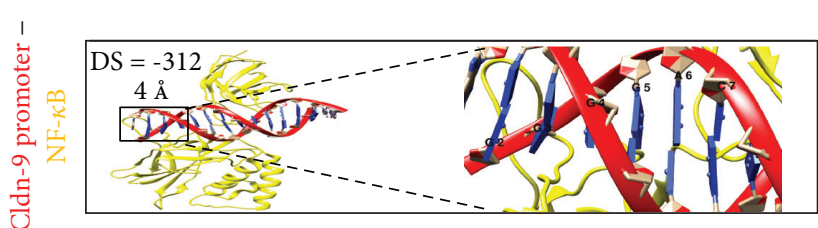

(b)

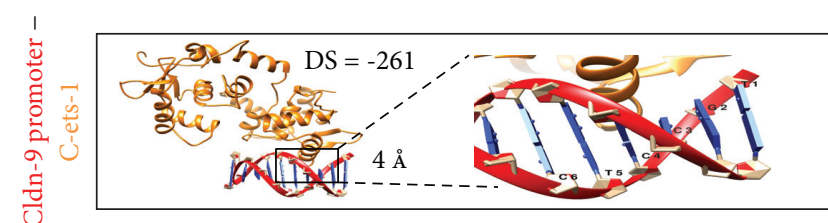

(d)

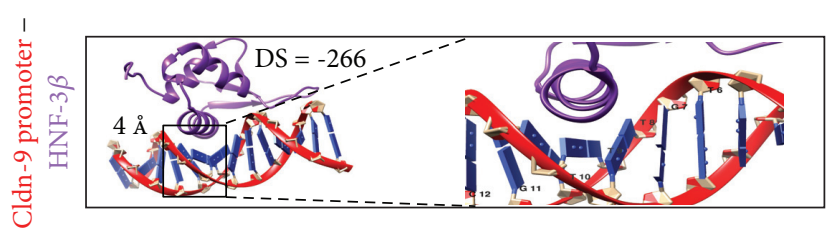

(e)

Figure 3: Molecular docking of the CLDN9 promoter region with transcription factors. Docking between the CLDN9 promoter (red/blue) and (a) Oct1 (green), (b) NF-kB (yellow), (c) AP1 (pink), (d) C-ets-1 (orange), and (e) HNF-3 $\beta$ (purple). Right side panels represent a zoom image of the interaction areas and the interacting nucleotides. DS = docking score. 


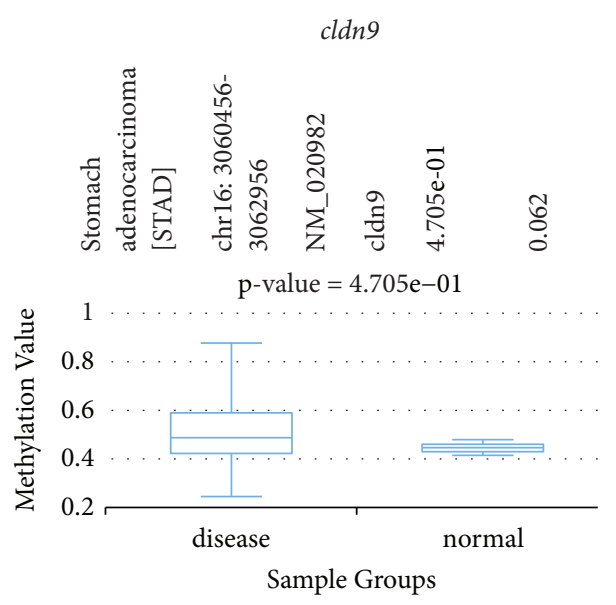

(a)

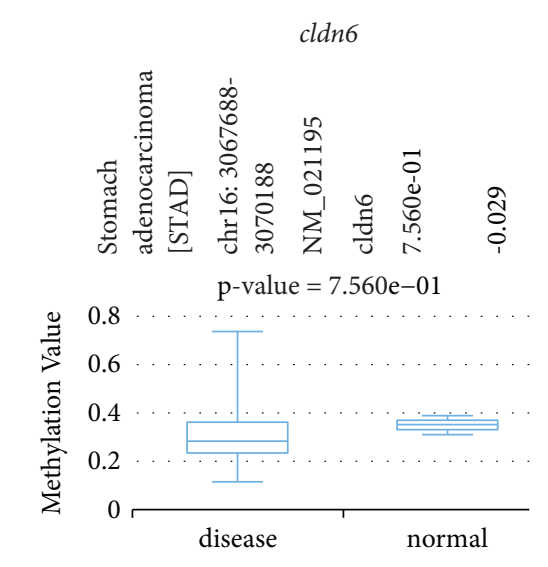

(b)

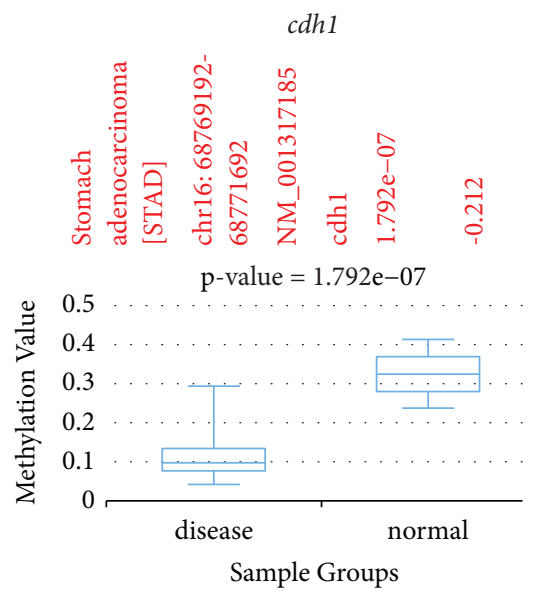

(c)

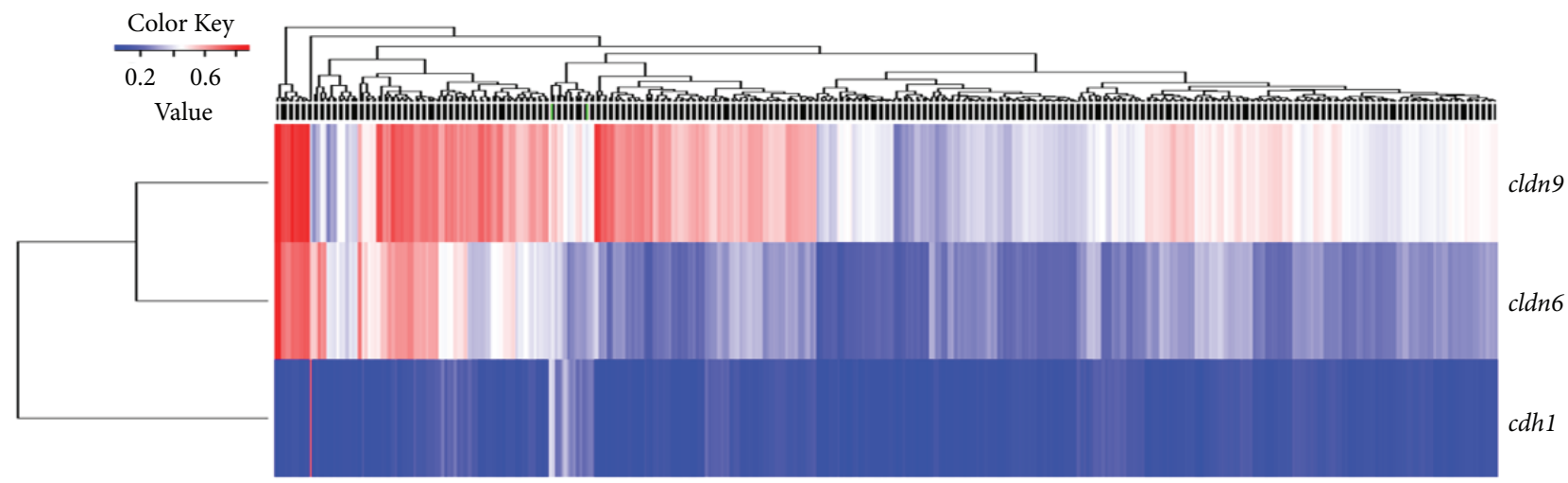

(d)

Figure 4: Continued. 


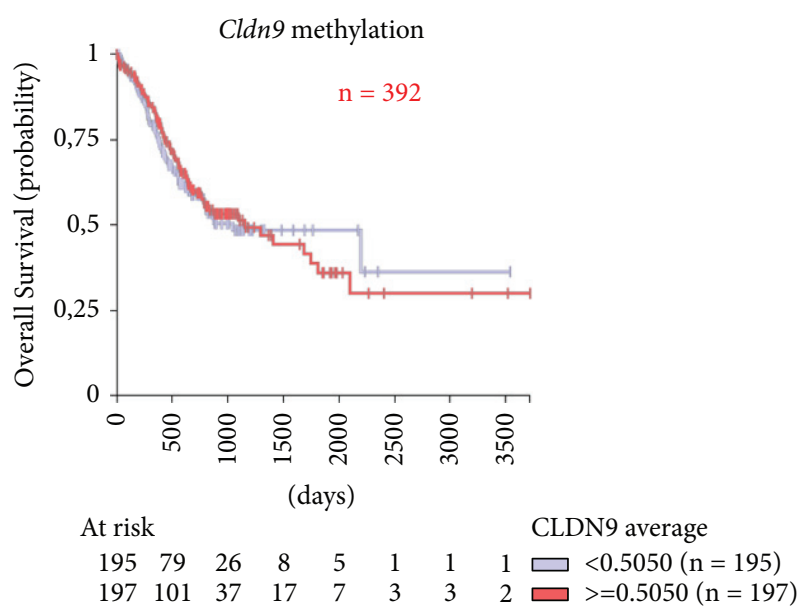

(e)
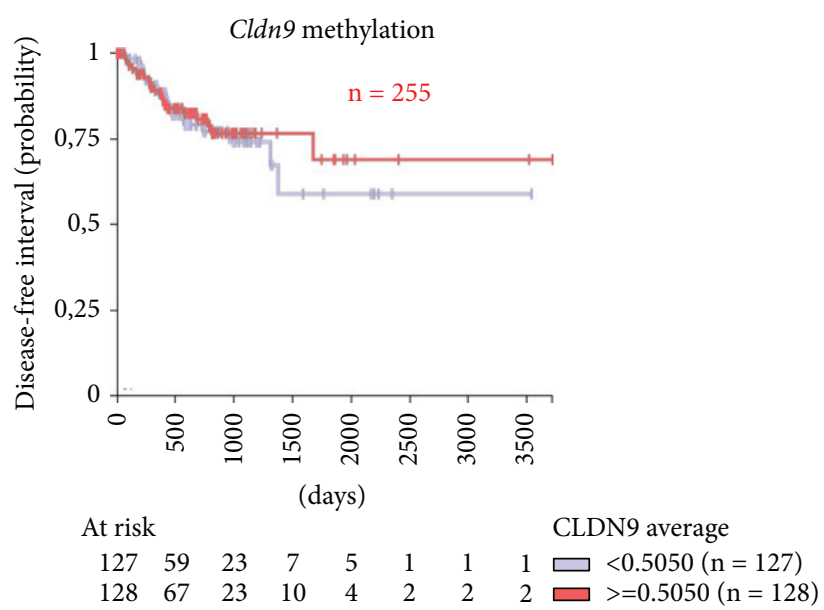

(f)

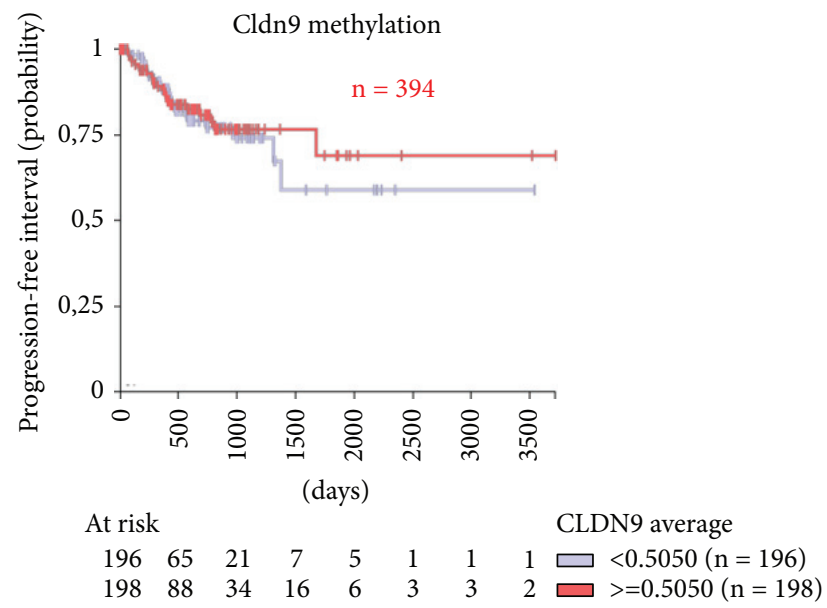

(g)

Figure 4: Methylation of CLDN9, CLDN6, and CDH1 genes. Methylation level of (a) CLDN9, (b) CLDN6, and (c) CDH1 under gastric cancer condition compared with normal tissue. (d) Heatmap of the methylation of CLDN9, CLDN6, and CDH1 genes. (e) Overall Survival probability between CLDN9 high-methylation level ( $\geq 0.5050$ average) vs. low-methylation level $(<0.5050$ average), $P=0.6871$, LogRank $=0.162$. (f) Disease-free interval between CLDN9 high-methylation level $(\geq 0.5050$ average) vs. low-methylation level $(<0.5050$ average), $P=0.7238$, Log-Rank $=0.125$. (g) Progression-free interval between CLDN9 high-methylation level ( $\geq 0.5050$ average) vs. lowmethylation level $(<0.5050$ average $), P=0.3450$, Log-Rank $=0.892$.

The radial graph (Figure 5(b)) shows that more progress has been made in the detection of the expression of Claudin9 in the tissues and cell types (0.75) than in the studies of the alteration in its expression (0.45), mentions in Pubmed (0.59), and the analysis of its transcription factors (0.45). The values below 0.7 are considered to have a low abundance of knowledge in the area.

3.6. Protein-Protein Interactions. The STRING interactome analysis showed that the first field of proteins with direct interaction or association with Claudin-9 is the claudin family proteins, such as Claudin-1, $-2,-3,-8,-10,-12,-15$, $-16,-18$, and -23 , among others. In the second field, the proteins with indirect interaction with Claudin-9 are proteins, such as Cadherin-1 (CDH1), Cadherin-5 (CDH5), Occludin (OCLN), ZO1 (TJP1), ZO5 (TJP5), EPCAM, CD81, or JAM-A (F11R), among others. These proteins participate in the positive regulation of the blood-brain barrier permeability, calcium-independent cell-cell adhesion via plasma membrane, the establishment of the intestinal endothelial barrier, TJ assembly, and protein relocalization to the TJ (Figure 6(a)) (Table 2).

An analysis of the physical interaction network of Claudin-9 using the BioGRID database [72] showed 17 proteins that physically interact with Claudin-9 (Figure 6(b)). These proteins are not the typical interactors for Claudin-9, which points to its participation in still unknown processes. For instance, GRM2 and LPAR3 proteins are $\mathrm{G}$ protein-coupled receptors that regulate glutamate and lysophosphatidic acid uptake, respectively, or RPRM (Reprimo protein) that modulates the arrest of the p53dependent cell cycle in the G2 phase.

Finally, an analysis of interactomes given by "textmining" between Claudin- 9 and the transcription factors determined using TFSearch made it possible to determine 


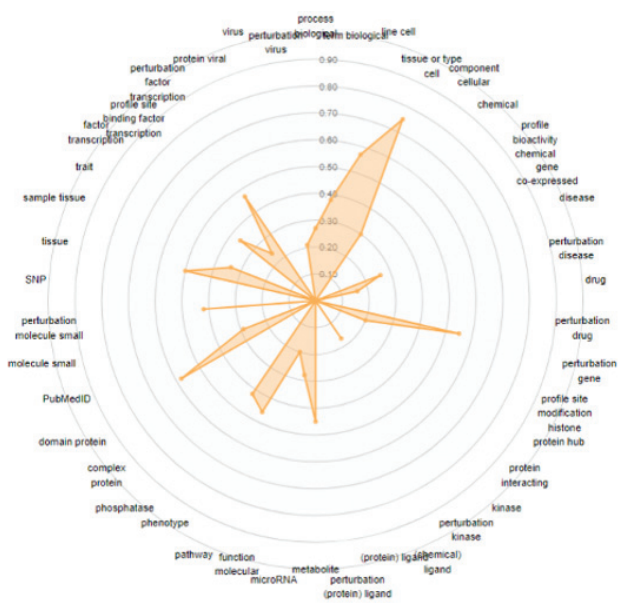

(b)

Figure 5: Sequence and structural analysis of Claudin-9. (a) Sequence comparison between Claudin-9 and those of other closely related claudins. The structural components of Claudin-9 are enlisted, and (b) the analysis of the knowledge of Claudin-9 based on its molecular components and characteristics, as well as its interactions.

a group of functions generally associated with four major cellular processes. (1) Cell junctions composed of other claudins. (2) Cell survival characterized by apoptotic or antiapoptotic processes, cell migration, and invasion processes; the most representative proteins involved in such processes were MAPK8, MAPK9, MAPK10, MAPK8IP1, and MMP9. (3) Cell differentiation and development, where the relevant proteins of these processes, such as the transcription factor Sox 5 that participates in invasion and metastasis in gastric cancer and Sox 9 that plays a role in gastric cancer development, were determined. Other important proteins in this group were the transcription factors FOXA1 and FOXA2 that have been reported as the initiating factors of a cellular transdifferentiation program that generates gastric-like tissue in lung adenocarcinomas. (4) Cellular transcription process, which included a great variety of transcription factors, such as USF1 that participates in familial combined hyperlipidemia, TCF3, which plays a significant role in $\mathrm{B}$ and $\mathrm{T}$ lymphopoiesis, or LMO2 that has a central role in erythropoiesis and hematopoietic development (Figure 6(c)).

3.7. Correlation with Survival in Gastric Cancer Patients. The overall survival of patients, based on the survival data from "The cancer genome Atlas (TCGA)" from the STAD study (TCGA Stomach Cancer), shows a significant positive effect $(P=0.004)$ in those patients with a lower expression of Claudin-9. Their median survival was 4.7 years compared to 1.6 years in the group with the highest expression (Figure $7(\mathrm{a})$ ).

The progression-free interval showed that patients with higher Claudin-9 expression have a worse prognosis, presenting disease progression at a median of 2.7 years compared to the 4.5 years observed for the low-expression group (Figure 7(b)).

\section{Discussion}

Claudins conform to a family of proteins with 27 human isoforms that play a crucial role in the regulation of cellular processes, such as growth, proliferation, migration, and invasion [14]. Most members of the claudin family share the same intracellular framework, however, the difference between them lies in their extracellular domains that regulate gate, barrier, and coreceptor diversity $[7,9,12,73]$. The CLDN9 gene has four introns and is located close to the CLDN6 gene in chromosome 16 [73]. It is considered, similar to CLDN6, a developmental claudin isoform [74]. Claudin-9 is expressed in the inner ear [25], where it acts as a cation barrier [75], a process essential for hearing, and it is also a coreceptor for hepatitis $C$ virus and $C$. perfringes enterotoxin $[76,77]$. Its RNA is poorly expressed in the stomach ( 0.3 average protein transcripts per million) although the protein level is not necessarily correlated with the mRNA level (The Human Protein Atlas) [78]. Claudin-9 is related to poor prognosis in gastric cancer $[23,30,31]$. Nevertheless, the prominence of Claudin-9 in relation to its interactions, activation, and role in gastric cancer is poorly described. Claudin-9 expression is related to the increased metastatic ability of the hepatocytes by disturbing the TyK2/Stat 3 signaling pathway [79], and it has been related to lymphatic metastasis in cervical carcinoma [28].

The results showed that the CLDN9 promoter possesses a minimal promoter region integrated by one GATA binding sequence, two GC boxes, the initiating region, and a distal promoter integrated by three CAAT boxes and two GATA binding sequences. The GC box sequences are considered the common transcriptional regulatory elements. The CAAT boxes signal the binding site for general transcription factors, and the sequences for the GATA factors serve as controllers for activating or repressing transcription [80]. It is possible that the function of the translated protein, 


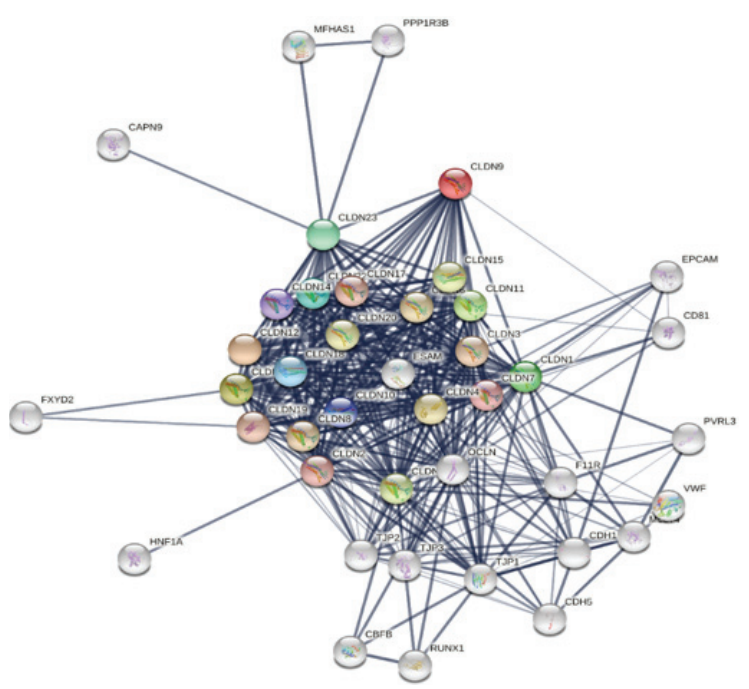

(a)

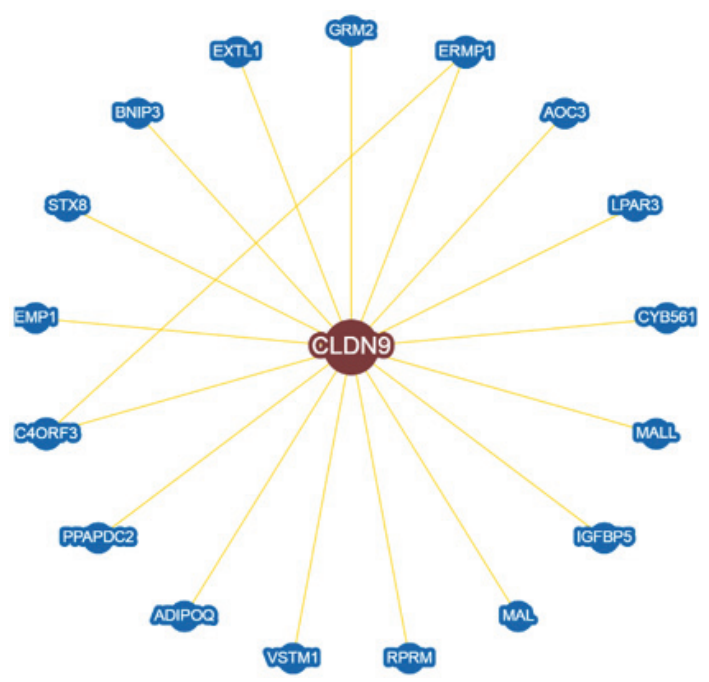

(b)

Figure 6: Continued. 


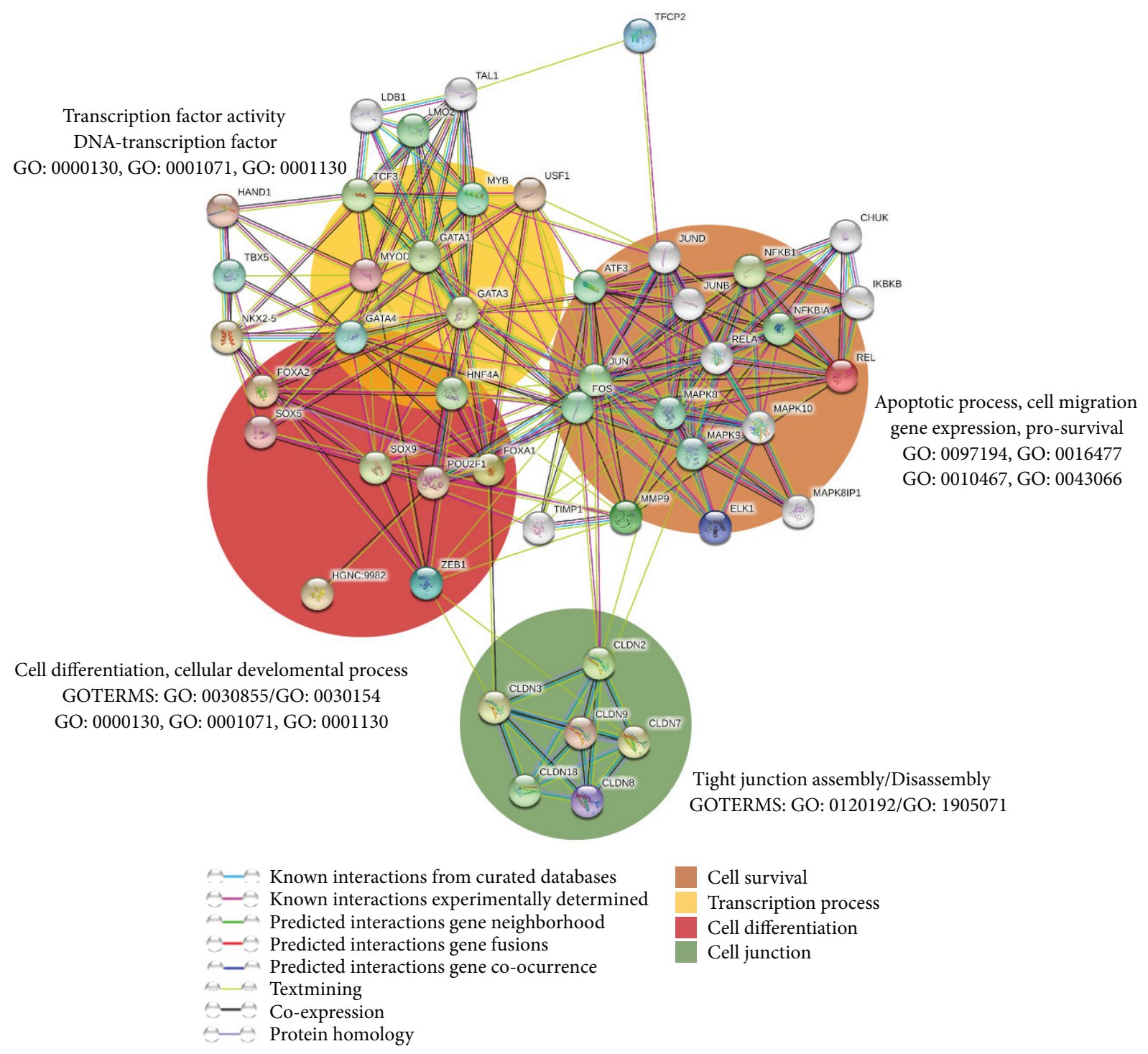

(c)

FIgURE 6: Protein-protein interaction network of Claudin-9. (a) The analysis of interaction by confidence using Reactome and (b) proteinprotein interaction network by STRING. The lines denote physical or theoretical interactions, field 1 to 10 , field 2 to 10 (the thicker the line and the closer they are to each other, the greater the interaction confidence), and (c) PPI interactions of Claudin-9 focused on related transcription factors. The background colored fields indicate functional affinity. The green field shows the functional affinity of the different claudins of the interaction network in the biological processes "Tight junction assembly/Disassmably (GOTERMS: GO: 0120192/GO: 1905071)." The red field shows the functional affinity of the transcription factors and other proteins participating in cell differentiation and the cell development process. The yellow field mainly shows the GATA transcription factors and other genes related to the development and progression of cancer, including gastric cancer.

cell proliferation and/or cell apoptosis, might be dependent on which promoter region binds a given transcription factor or its binding kinetics [81]. It is also possible that the binding of both promoter regions by the same transcription factor by a mediator and a modification complex is required to form a loop that initiates protein transcription [82]. It has been established that a change in the transcription factor activity dependent on the transcription factor concentration alters the expression of its targets [83].

Interestingly, 20 different transcription factors that can bind the CLDN9 promoter region with a $100 \%$ score were determined. The majority are considered the key regulators of epithelial differentiation and organ development, i.e., CP2 [84], the maintenance of the germline stem cells, i.e., USF [85], enhancers that activate transcriptional programs and cellular reprogramming, i.e., GATA1 and GATA 3 [86], favor cell growth and proliferation, i.e., AP1 and AP4 [87], and facilitate TJ formation in carcinoma cells, i.e., HNF4 [88].

ChiP-Atlas MACS2 analysis found that GATA6 and GATA4 regulate CLDN9 expression in the YCC3 and AGS gastric epithelial cancer cell lines, respectively, whereas KLF5, a transcription factor that binds to the GC boxes [89] and 
TABLE 2: STRING interactome.

\begin{tabular}{|c|c|c|c|c|}
\hline Protein & Function & $\begin{array}{c}\text { Type of } \\
\text { interaction }\end{array}$ & Curated & References \\
\hline EPCAM & $\begin{array}{c}\text { The epithelial cell adhesion molecule's precursor participates in migration, } \\
\text { proliferation, and cellular differentiation. In cancer, it promotes tumor } \\
\text { progression by the EGFR pathway. }\end{array}$ & Textmining & STRING & {$[33,34]$} \\
\hline CD81 & $\begin{array}{l}\text { The tetraspanin family is a cell-surface protein and plays an essential role in } \\
\text { developing cellular growth and activating the B and T cells. It is expressed in most } \\
\text { types of cancers. }\end{array}$ & Textmining & STRING & {$[35,36]$} \\
\hline PVRL3 & $\begin{array}{l}\text { Poliovirus receptor-related } 3 \text {, also called Nectin-3, forms part of the adherens } \\
\text { junctions. PVLR3 has been implicated in tumor progression in lung, pancreatic, } \\
\text { and ovarian adenocarcinomas. }\end{array}$ & Textmining & STRING & [37-39] \\
\hline VWF & $\begin{array}{l}\text { Von Willebrand factor, its primary role is in thrombus formation and blood } \\
\text { coagulation. VWF has been reported to participate in inflammation, angiogenesis, } \\
\text { and metastasis in various cancers, including gastric cancer. }\end{array}$ & Textmining & STRING & {$[40,41]$} \\
\hline F11R & $\begin{array}{l}\text { Junctional adhesion molecule A (JAM-A) plays a role in the epithelial tight } \\
\text { junction formation. JAM-A has been reported to promote proliferation and } \\
\text { inhibit apoptosis in gastric cancer. }\end{array}$ & Textmining & STRING & {$[42,43]$} \\
\hline CDH5 & $\begin{array}{l}\text { Cadherin-5, this protein plays a role in endothelial adherens junction assembly } \\
\text { and maintenance. In cancer, it has been reported to be involved in progression and } \\
\text { metastasis. In gastric cancer, its expression correlates with poor survival. }\end{array}$ & Textmining & STRING & [44-46] \\
\hline $\begin{array}{l}\text { TJP1, TJP2, } \\
\text { TJP3 }\end{array}$ & $\begin{array}{l}\text { Tight junction proteins } \mathrm{ZO}-1, \mathrm{ZO}-2 \text {, and } \mathrm{ZO}-3 \text { are closely related scaffolding } \\
\text { proteins that link the tight junction (TJ) transmembrane proteins, such as } \\
\text { claudins, junctional adhesion molecules, and occludin to the actin cytoskeleton. } \\
\text { Their expression is altered during tumor development, metastasis, and poor } \\
\text { prognosis in several types of cancers. }\end{array}$ & Texmining & STRING & {$[47-52]$} \\
\hline OCLN & $\begin{array}{l}\text { Occludin may play a role in forming and regulating the tight junction (TJ) } \\
\text { paracellular permeability barrier. In gastric cancer, the downregulation of some } \\
\text { occludins is associated with tumor aggressiveness and survival. }\end{array}$ & Texmining & STRING & {$[53,54]$} \\
\hline RUNX1 & $\begin{array}{l}\text { Runt-related transcription factor } 1 \text { is a transcription factor that modulates the } \\
\text { target genes involved in the development of immune cells. In colorectal cancer, it } \\
\text { promotes tumor metastasis by activating the Wnt/ } \beta \text {-catenin signaling pathway } \\
\text { and EMT. }\end{array}$ & Textmining & STRING & [55-57] \\
\hline CBFB & $\begin{array}{l}\text { Core-binding factor subunit beta, a non-DNA-binding regulatory subunit that } \\
\text { allosterically enhances the sequence-specific DNA-binding capacity of } \\
\text { RUNX-involved in hematopoiesis and osteogenesis. In breast cancer, it has been } \\
\text { observed as a tumor suppressor. }\end{array}$ & Textmining & STRING & {$[58,59]$} \\
\hline HNF1A & $\begin{array}{c}\text { Hepatocyte nuclear factor 1-alpha is a transcriptional activator that regulates the } \\
\text { tissue-specific expression of multiple genes, especially in the pancreatic islet cells } \\
\text { and the liver. Recently, it has been reported to facilitate gastric cancer tumor } \\
\text { progression. }\end{array}$ & Textmining & STRING & {$[60,61]$} \\
\hline FXYD2 & $\begin{array}{l}\text { Sodium/potassium-transporting ATPase subunit gamma may form the receptor } \\
\text { site for cardiac glycoside binding or modulating the sodium ATPase's transport } \\
\text { function. It may be involved in tumor growth. }\end{array}$ & Textmining & STRING & {$[62,63]$} \\
\hline CAPN9 & $\begin{array}{l}\text { Calpain-9 is involved in apoptosis, cellular proliferation, and cell motility. Calpain } \\
\text { expression is altered during tumorigenesis and the proteolysis of numerous } \\
\text { substrates, such as inhibitors of nuclear factor- } \kappa \mathrm{B} \text { and proto-oncogenes. }\end{array}$ & Texmining & STRING & [64-66] \\
\hline MFHAS1 & $\begin{array}{l}\text { Malignant fibrous histiocytoma-amplified sequence } 1 \text { functions in innate } \\
\text { immunity, more specifically, in the inflammatory response as a regulator of the } \\
\text { Toll-like receptor TLR2 and TLR } 4 \text { signaling pathways. MFHAS1 promotes } \\
\text { colorectal cancer progress by regulating the polarization of tumor-associated } \\
\text { macrophages via the STAT6 signaling pathway }\end{array}$ & Textmining & STRING & {$[67,68]$} \\
\hline PPP1R3B & $\begin{array}{l}\text { Protein phosphatase } 1 \text { regulatory subunit } 3 \mathrm{~B} \text { acts as a glycogen-targeting subunit } \\
\text { for phosphatase } \mathrm{PP} 1 \text { and promotes glycogen synthesis. In cancer, it has been used } \\
\text { to treat a melanoma patient with an immunological focus. }\end{array}$ & Textmining & STRING & {$[69,70]$} \\
\hline ESAM & $\begin{array}{l}\text { Endothelial cell-selective adhesion molecule's in vitro functional profile strongly } \\
\text { suggests a role in cell-cell interactions critical for vascular development or } \\
\text { function. }\end{array}$ & Textmining & STRING & [71] \\
\hline
\end{tabular}




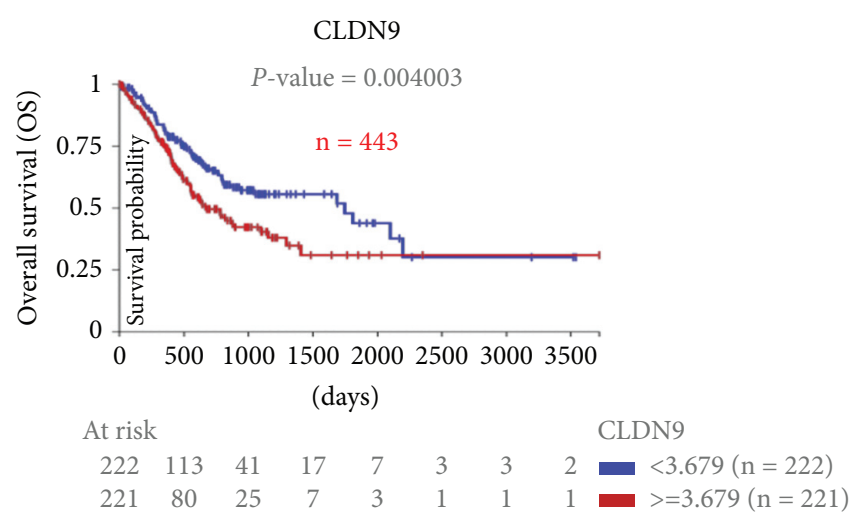

(a)

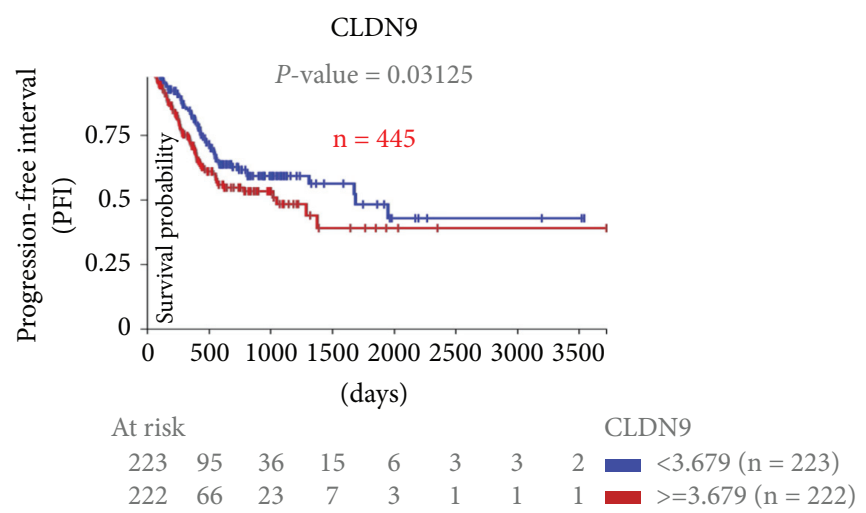

(b)

Figure 7: Expression of Claudin-9 and its clinical impact. (a) Claudin-9 expression and Overall Survival based on a high ( $\geq 3.679)$ vs. low $(<3.679)$ expression, (b) Progression-free interval based on high $(\geq 3.679)$ vs. low $(<3.679)$ Claudin-9 expression.

interacts with GATA4 and GATA6 [90] was the regulator in KATO III gastric cancer cells. It is possible that the difference may arise from the different histopathological phenotypes because KATO III is a human gastric signet ring cell adenoma cancer that can be induced to adipogenic, chondrogenic, osteogenic, and neurogenic differentiation [91].

A different analysis showed that the CLDN9 gene was highly methylated and the heat map results showed the transcriptional repression of the CLDN9 gene expression in gastric cancer patients. DNA methylation is an epigenetic mechanism recognized as a biological process that can change the activity of a DNA segment, silencing gene expression [92]. Some genes can be expressed even when they are extensively methylated $[93,94]$. In relation to gastric cancer, the hypermethylation of the Claudin-11 promoter has been associated with increased invasive potential [95], and the hypermethylation of the Claudin-3 promoter is considered a predictor of poor prognosis in advanced gastric adenocarcinoma [96]. In fact, promoter hypermethylation and claudin expression have been associated with gastric cancer TNM stage [97, 98].

As expected, Claudin-9 expression is associated with shorter and progression-free survival. The expression of dedifferentiation markers, such as CD44, CD133, Claudin-6 or -9 , in the majority of epithelial cancers [99-103] is associated with poor survival.

\section{Conclusion}

Claudin-9 is a TJ protein involved in key biological processes. Its expression may be regulated by many mechanisms, however, its overexpression or the methylation status of the promoter may be a prognostic factor in gastric cancer.

\section{Data Availability}

The data used to support the findings of this study are available from the corresponding author upon request.

\section{Conflicts of Interest}

The authors declare that none of them has conflicts of interest.

\section{Acknowledgments}

Elizabeth Hernández-Nava was a recipient of a postdoctoral fellowship by the Consejo Nacional de Ciencia y Tecnología of México (CONACYT). This work was supported by the Programa de Apoyo a Proyectos de Investigación e Innovación Tecnológica (PAPIT) of the Universidad Nacional Autónoma de México (UNAM) grants IN218019 and IN221519.

\section{References}

[1] J. Ferlay, M. Colombet, I. Soerjomataram et al., "Estimating the global cancer incidence and mortality in 2018: GLOBOCAN sources and methods," International Journal of Cancer, vol. 144, no. 8, pp. 1941-1953, 2019.

[2] V. De Re, "Molecular features distinguish gastric cancer subtypes," International Journal of Molecular Sciences, vol. 19, 2018.

[3] Y. Ling, Y. Watanabe, M. Nagahashi et al., "Genetic profiling for diffuse type and genomically stable subtypes in gastric cancer," Computational and Structural Biotechnology Journal, vol. 18, pp. 3301-3308, 2020.

[4] K. H. R. Puneet, H. R. Kazmi, S. Kumari, S. Tiwari, A. Khanna, and G. Narayan, "Epigenetic mechanisms and events in gastric cancer-emerging novel biomarkers," Pathology and Oncology Research, vol. 24, no. 4, pp. 757-770, 2018.

[5] A. Colaprico, C. Olsen, M. H. Bailey et al., "Interpreting pathways to discover cancer driver genes with moonlight," Nature Communications, vol. 11, no. 1, p. 69, 2020.

[6] M. F. Berger and E. R. Mardis, "The emerging clinical relevance of genomics in cancer medicine," Nature Reviews Clinical Oncology, vol. 15, no. 6, pp. 353-365, 2018.

[7] J. M. Anderson and C. M. Van Itallie, "Physiology and function of the tight junction," Cold Spring Harbor Perspectives in Biology, vol. 1, no. 2, Article ID a002584, 2009.

[8] U. Heinemann and A. Schuetz, "Structural features of tightjunction proteins," International Journal of Molecular Sciences, vol. 20, 2019.

[9] D. Günzel and A. S. Yu, "Claudins and the modulation of tight junction permeability," Physiological Reviews, vol. 93, pp. 525-569, 2013.

[10] J. Li, "Dysregulated expression of claudins in cancer (review)," Oncology Letters, vol. 22, no. 3, p. 641, 2021. 
[11] A. Taylor, M. Warner, C. Mendoza et al., "Chimeric claudins: a new tool to study tight junction structure and function," International Journal of Molecular Sciences, vol. 22, 2021.

[12] T. Otani, T. P. Nguyen, S. Tokuda et al., "Claudins and JAMA coordinately regulate tight junction formation and epithelial polarity," Journal of Cell Biology, vol. 218, no. 10, pp. 3372-3396, 2019.

[13] A. A. Bhat, S. Uppada, I. W. Achkar et al., "Tight junction proteins and signaling pathways in cancer and inflammation: a functional crosstalk," Frontiers in Physiology, vol. 9, p. 1942, 2018.

[14] S. Gowrikumar, A. B. Singh, and P. Dhawan, "Role of claudin proteins in regulating cancer stem cells and chemoresistance-potential implication in disease prognosis and therapy," International Journal of Molecular Sciences, vol. 21, 2019.

[15] M. Kwon, "Emerging roles of claudins in human cancer," International Journal of Molecular Sciences, vol. 14, no. 9, pp. 18148-18180, 2013.

[16] E. Salvador, M. Burek, and C. Y. Förster, "Tight junctions and the tumor microenvironment," Current Pathobiology Reports, vol. 4, no. 3, pp. 135-145, 2016.

[17] M. Osanai, A. Takasawa, M. Murata, and N. Sawada, "Claudins in cancer: bench to bedside," Pflügers Archiv-European Journal of Physiology, vol. 469, no. 1, pp. 55-67, 2017.

[18] L. L. Eftang, Y. Esbensen, T. M. Tannæs, G. P. Blom, I. R. Bukholm, and G. Bukholm, "Up-regulation of CLDN1 in gastric cancer is correlated with reduced survival," $B M C$ Cancer, vol. 13, no. 1, p. 586, 2013.

[19] H. Jung, K. H. Jun, J. H. Jung, H. M. Chin, and W. B. Park, "The expression of claudin-1, claudin-2, claudin-3, and claudin-4 in gastric cancer tissue," Journal of Surgical Research, vol. 167, no. 2, pp. e185-e191, 2011.

[20] H. Zayed, "The identification of highly upregulated genes in claudin-low breast cancer through an integrative bioinformatics approach," Computers in Biology and Medicine, vol. 127, Article ID 103806, 2020.

[21] M. Gao, W. Li, H. Wang, and G. Wang, "The distinct expression patterns of claudin-10, -14, -17 and E-cadherin between adjacent non-neoplastic tissues and gastric cancer tissues," Diagnostic Pathology, vol. 8, no. 1, p. 205, 2013.

[22] T.-L. Hwang, T.-T. Changchien, C.-C. Wang, and C.-M. Wu, "Claudin-4 expression in gastric cancer cells enhances the invasion and is associated with the increased level of matrix metalloproteinase-2 and -9 expression," Oncology Letters, vol. 8, no. 3, pp. 1367-1371, 2014.

[23] T. Kohmoto, K. Masuda, K. Shoda et al., "Claudin-6 is a single prognostic marker and functions as a tumor-promoting gene in a subgroup of intestinal type gastric cancer," Gastric Cancer, vol. 23, no. 3, pp. 403-417, 2020.

[24] K.-H. Jun, J.-H. Kim, J.-H. Jung, H.-J. Choi, and H.-M. Chin, "Expression of claudin-7 and loss of claudin-18 correlate with poor prognosis in gastric cancer," International Journal of Surgery, vol. 12, no. 2, pp. 156-162, 2014.

[25] S.-i. Kitajiri, M. Furuse, K. Morita et al., "Expression patterns of claudins, tight junction adhesion molecules, in the inner ear," Hearing Research, vol. 187, no. 1-2, pp. 25-34, 2004.

[26] R. K. Sharma, Z. S. Chheda, B. P. Das Purkayastha, J. G. Gomez-Gutierrez, V. R. Jala, and B. Haribabu, "A spontaneous metastasis model reveals the significance of claudin-9 overexpression in lung cancer metastasis," Clinical \& Experimental Metastasis, vol. 33, no. 3, pp. 263-275, 2016.
[27] L. Hong, Y. Wu, J. Feng et al., "Overexpression of the cell adhesion molecule claudin-9 is associated with invasion in pituitary oncocytomas," Human Pathology, vol. 45, no. 12, pp. 2423-2429, 2014.

[28] J. Zhu, R. Wang, H. Cao et al., "Expression of claudin-5, -7, -8 and -9 in cervical carcinoma tissues and adjacent nonneoplastic tissues," International Journal of Clinical and Experimental Pathology, vol. 8, pp. 9479-9486, 2015.

[29] H. Kang, N. Wang, X. Wang et al., "A glycolysis-related gene signature predicts prognosis of patients with esophageal adenocarcinoma," Aging, vol. 12, no. 24, pp. 25828-25844, 2020.

[30] E. Rendón-Huerta, F. Teresa, G. M. Teresa et al., "Distribution and expression pattern of claudins 6, 7, and 9 in diffuse- and intestinal-type gastric adenocarcinomas," Journal of Gastrointestinal Cancer, vol. 41, pp. 52-59, 2010.

[31] V. E. Zavala-Zendejas, A. C. Torres-Martinez, B. SalasMorales, T. I. Fortoul, L. F. Montaño, and E. P. RendonHuerta, "Claudin-6, 7, or 9 overexpression in the human gastric adenocarcinoma cell line AGS increases its invasiveness, migration, and proliferation rate," Cancer Investigation, vol. 29, no. 1, pp. 1-11, 2011.

[32] C. Combet, C. Blanchet, C. Geourjon, and G. Deléage, "NPS@: network protein sequence analysis," Trends in Biochemical Sciences, vol. 25, no. 3, pp. 147-150, 2000.

[33] L. Huang, Y. Yang, F. Yang et al., "Functions of EpCAM in physiological processes and diseases (review)," International Journal of Molecular Medicine, vol. 42, pp. 1771-1785, 2018.

[34] H.-N. Chen, K.-H. Liang, J.-K. Lai et al., "EpCAM signaling promotes tumor progression and protein stability of PD-L1 through the EGFR pathway," Cancer Research, vol. 80, no. 22, pp. 5035-5050, 2020.

[35] S. Levy, "Function of the tetraspanin molecule CD81 in B and T cells," Immunologic Research, vol. 58, no. 2-3, pp. 179-185, 2014.

[36] F. Vences-Catalán, C. Duault, C.-C. Kuo, R. Rajapaksa, R. Levy, and S. Levy, "CD81 as a tumor target," Biochemical Society Transactions, vol. 45, no. 2, pp. 531-535, 2017.

[37] T. Fujito, W. Ikeda, S. Kakunaga et al., "Inhibition of cell movement and proliferation by cell-cell contact-induced interaction of Necl-5 with nectin-3," Journal of Cell Biology, vol. 171, no. 1, pp. 165-173, 2005.

[38] H. Izumi, K. Hirabayashi, N. Nakamura, and T. Nakagohri, "Nectin expression in pancreatic adenocarcinoma: nectin-3 is associated with a poor prognosis," Surgery Today, vol. 45, no. 4, pp. 487-494, 2015.

[39] F. Xu, X. Si, J. Wang, A. Yang, T. Qin, and Y. Yang, "Nectin-3 is a new biomarker that mediates the upregulation of MMP2 and MMP9 in ovarian cancer cells," Biomedicine \& Pharmacotherapy, vol. 110, pp. 139-144, 2019.

[40] M. I. Hassan, A. Saxena, and F. Ahmad, "Structure and function of von Willebrand factor," Blood Coagulation and Fibrinolysis, vol. 23, no. 1, pp. 11-22, 2012.

[41] S. Patmore, S. P. S. Dhami, and J. M. O’Sullivan, "Von Willebrand factor and cancer; metastasis and coagulopathies," Journal of Thrombosis and Haemostasis, vol. 18, no. 10, pp. 2444-2456, 2020.

[42] M. B. Sobocka, T. Sobocki, P. Banerjee et al., "Cloning of the human platelet F11 receptor: a cell adhesion molecule member of the immunoglobulin superfamily involved in platelet aggregation," Blood, vol. 95, no. 8, pp. 2600-2609, 2000.

[43] K. Ikeo, T. Oshima, J. Shan et al., "Junctional adhesion molecule-A promotes proliferation and inhibits apoptosis of 
gastric cancer," Hepato-Gastroenterology, vol. 62, pp. 540545, 2015.

[44] J. Brasch, O. J. Harrison, G. Ahlsen et al., "Structure and binding mechanism of vascular endothelial cadherin: a divergent classical cadherin," Journal of Molecular Biology, vol. 408, no. 1, pp. 57-73, 2011.

[45] J. I. Casal and R. A. Bartolomé, "Beyond N-cadherin, relevance of cadherins 5, 6 and 17 in cancer progression and metastasis," International Journal of Molecular Sciences, vol. 20, 2019.

[46] K. Higuchi, M. Inokuchi, Y. Takagi et al., "Cadherin 5 expression correlates with poor survival in human gastric cancer," Journal of Clinical Pathology, vol. 70, no. 3, pp. 217-221, 2017.

[47] J. Kremerskothen, M. Stölting, C. Wiesner et al., “Zona occludens proteins modulate podosome formation and function," The FASEB Journal, vol. 25, no. 2, pp. 505-514, 2011.

[48] A. Chlenski, K. V. Ketels, G. I. Korovaitseva, M. S. Talamonti, R. Oyasu, and D. G. Scarpelli, "Organization and expression of the human zo-2 gene (tjp-2) in normal and neoplastic tissues," Biochimica et Biophysica Acta (BBA)-Gene Structure and Expression, vol. 1493, no. 3, pp. 319-324, 2000.

[49] C. T. Capaldo, S. Koch, M. Kwon, O. Laur, C. A. Parkos, and A. Nusrat, "Tight function zonula occludens-3 regulates cyclin D1-dependent cell proliferation," Molecular Biology of the Cell, vol. 22, no. 10, pp. 1677-1685, 2011.

[50] S. H. Lee, A. R. Paek, K. Yoon, S. H. Kim, S. Y. Lee, and H. J. You, "Tight junction protein 1 is regulated by transforming growth factor- $\beta$ and contributes to cell motility in NSCLC cells," BMB Reports, vol. 48, no. 2, pp. 115-120, 2015.

[51] X. Tan, L. Zhou, W. Wang et al., "Genomic analysis of invasionmetastasis-related factors in pancreatic cancer cells," Experimental and Therapeutic Medicine, vol. 1, pp. 211-216, 2010.

[52] T. A. Martin, G. Watkins, R. E. Mansel, and W. G. Jiang, "Corrigendum to "loss of tight junction plaque molecules in breast cancer tissues is associated with a poor prognosis in patients with breast cancer" [Eur j cancer 40 (18) (2004) 2717-2725]," European Journal of Cancer, vol. 88, pp. 115-116, 2018.

[53] T. Suzuki, B. C. Elias, A. Seth et al., "PKC regulates occludin phosphorylation and epithelial tight junction integrity," Proceedings of the National Academy of Sciences, vol. 106, no. 1, pp. 61-66, 2009.

[54] S. Ohtani, M. Terashima, J. Satoh et al., "Expression of tightjunction-associated proteins in human gastric cancer: downregulation of claudin- 4 correlates with tumor aggressiveness and survival," Gastric Cancer, vol. 12, no. 1, pp. 43-51, 2009.

[55] T. Fujimoto, K. Anderson, S. E. W. Jacobsen, S.-i. Nishikawa, and C. Nerlov, "Cdk6 blocks myeloid differentiation by interfering with Runx1 DNA binding and Runx1-C/EBP $\alpha$ interaction," The EMBO Journal, vol. 26, no. 9, pp. 2361-2370, 2007.

[56] M. Ono, H. Yaguchi, N. Ohkura et al., "Foxp3 controls regulatory T-cell function by interacting with AML1/ Runx1," Nature, vol. 446, no. 7136, pp. 685-689, 2007.

[57] Q. Li, Q. Lai, C. He et al., "RUNX1 promotes tumour metastasis by activating the $\mathrm{Wnt} / \beta$-catenin signalling pathway and EMT in colorectal cancer," Journal of Experimental \& Clinical Cancer Research, vol. 38, no. 1, p. 334, 2019.

[58] N. Adya, L. H. Castilla, and P. P. Liu, "Function of CBF $\beta /$ Bro proteins," Seminars in Cell \& Developmental Biology, vol. 11, no. 5, pp. 361-368, 2000.
[59] N. Malik, H. Yan, N. Moshkovich et al., "The transcription factor CBFB suppresses breast cancer through orchestrating translation and transcription," Nature Communications, vol. 10, no. 1, p. 2071, 2019.

[60] R. B. Rose, J. H. Bayle, J. A. Endrizzi, J. D. Cronk, G. R. Crabtree, and T. Alber, "Structural basis of dimerization, coactivator recognition and MODY3 mutations in HNFlalpha," Nature Structural Biology, vol. 7, pp. 744-748, 2000.

[61] P. Ma, L. Li, F. Liu, and Q. Zhao, "HNF1A-Induced lncRNA HCG18 facilitates gastric cancer progression by upregulating DNAJB12 via miR-152-3p," OncoTargets and Therapy, vol. 13, pp. 7641-7652, 2020.

[62] K. Geering, "Function of FXYD proteins, regulators of $\mathrm{Na}$, K-ATPase," Journal of Bioenergetics and Biomembranes, vol. 37, no. 6, pp. 387-392, 2005.

[63] I.-L. Hsu, C.-Y. Chou, Y.-Y. Wu et al., "Targeting FXYD2 by cardiac glycosides potently blocks tumor growth in ovarian clear cell carcinoma," Oncotarget, vol. 7, no. 39, pp. 62925-62938, 2016.

[64] H. R. Momeni, "Role of calpain in apoptosis," Cell Journal, vol. 13, pp. 65-72, 2011.

[65] Y. Zhang, N. M. Liu, Y. Wang, J. Y. Youn, and H. Cai, "Endothelial cell calpain as a critical modulator of angiogenesis," Biochimica et Biophysica Acta-Molecular Basis of Disease, vol. 1863, no. 6, pp. 1326-1335, 2017.

[66] S. J. Storr, N. O. Carragher, M. C. Frame, T. Parr, and S. G. Martin, "The calpain system and cancer," Nature Reviews Cancer, vol. 11, no. 5, pp. 364-374, 2011.

[67] J. Zhong, Q.-Q. Shi, M.-M. Zhu et al., "MFHAS1 is associated with sepsis and stimulates TLR2/NF- $\kappa$ B signaling pathway following negative regulation," PLoS One, vol. 10, no. 11, Article ID e0143662, 2015.

[68] W. Chen, Y. Xu, J. Zhong et al., "MFHAS1 promotes colorectal cancer progress by regulating polarization of tumorassociated macrophages via STAT6 signaling pathway," Oncotarget, vol. 7, no. 48, pp. 78726-78735, 2016.

[69] M. B. Mehta, S. V. Shewale, R. N. Sequeira, J. S. Millar, N. J. Hand, and D. J. Rader, "Hepatic protein phosphatase 1 regulatory subunit 3B (Ppp1r3b) promotes hepatic glycogen synthesis and thereby regulates fasting energy homeostasis," Journal of Biological Chemistry, vol. 292, no. 25, pp. 10444-10454, 2017.

[70] Y.-C. Lu, X. Yao, Y. F. Li et al., "Mutated PPP1R3B is recognized by $\mathrm{T}$ cells used to treat a melanoma patient who experienced a durable complete tumor regression," The Journal of Immunology, vol. 190, no. 12, pp. 6034-6042, 2013.

[71] K.-i. Hirata, T. Ishida, K. Penta et al., "Cloning of an immunoglobulin family adhesion molecule selectively expressed by endothelial cells," Journal of Biological Chemistry, vol. 276, no. 19, pp. 16223-16231, 2001.

[72] K. Luck, D.-K. Kim, L. Lambourne et al., "A reference map of the human binary protein interactome," Nature, vol. 580, no. 7803, pp. 402-408, 2020.

[73] G. Krause, L. Winkler, S. L. Mueller, R. F. Haseloff, J. Piontek, and I. E. Blasig, "Structure and function of claudins," Biochimica et Biophysica Acta (BBA)-Biomembranes, vol. 1778, no. 3, pp. 631-645, 2008.

[74] G. Abuazza, A. Becker, S. S. Williams et al., "Claudins 6, 9, and 13 are developmentally expressed renal tight junction proteins," American Journal of Physiology - Renal Physiology, vol. 291, no. 6, pp. F1132-F1141, 2006.

[75] Y. Nakano, S. H. Kim, H.-M. Kim et al., "A claudin-9-based ion permeability barrier is essential for hearing," PLoS Genetics, vol. 5, no. 8, Article ID e1000610, 2009. 
[76] I. Fofana, L. Zona, C. Thumann et al., "Functional analysis of claudin- 6 and claudin- 9 as entry factors for hepatitis $C$ virus infection of human hepatocytes by using monoclonal antibodies," Journal of Virology, vol. 87, no. 18, pp. 10405-10410, 2013.

[77] A. J. Vecchio and R. M. Stroud, "Claudin-9 structures reveal mechanism for toxin-induced gut barrier breakdown," Proceedings of the National Academy of Sciences, vol. 116, no. 36, pp. 17817-17824, 2019.

[78] M. Uhlén, L. Fagerberg, B. M. Hallström et al., "Proteomics. Tissue-based map of the human proteome," Science, vol. 347, no. 6220, Article ID 1260419, 2015.

[79] H. Liu, M. Wang, M. Wang, N. Liang, and L. Guan, "Claudin-9 enhances the metastatic potential of hepatocytes via Tyk2/Stat3 signaling," Turkish Journal of Gastroenterology, vol. 30, no. 8, pp. 722-732, 2019.

[80] M. H. Lentjes, H. E. Niessen, Y. Akiyama, A. P. de Bruïne, V. Melotte, and M. van Engeland, "The emerging role of GATA transcription factors in development and disease," Expert Reviews in Molecular Medicine, vol. 18, p. e3, 2016.

[81] M. J. Culyba, "Ordering up gene expression by slowing down transcription factor binding kinetics," Current Genetics, vol. 65, no. 2, pp. 401-406, 2019.

[82] J. A. D'Alessio, K. J. Wright, and R. Tjian, "Shifting players and paradigms in cell-specific transcription," Molecular Cell, vol. 36, no. 6, pp. 924-931, 2009.

[83] L. B. Carey, D. van Dijk, P. M. A. Sloot, J. A. Kaandorp, and E. Segal, "Promoter sequence determines the relationship between expression level and noise," PLoS Biology, vol. 11, no. 4, Article ID e1001528, 2013.

[84] Q. Ming, Y. Roske, A. Schuetz et al., "Structural basis of gene regulation by the Grainyhead/CP2 transcription factor family," Nucleic Acids Research, vol. 46, no. 4, pp. 2082-2095, 2018.

[85] I. Faisal, S. Cisneros-Montalvo, G. Hamer et al., "Transcription factor USF1 is required for maintenance of germline stem cells in male mice," Endocrinology, vol. 160, no. 5, pp. 1119-1136, 2019.

[86] H. Tanaka, Y. Takizawa, M. Takaku et al., "Interaction of the pioneer transcription factor GATA3 with nucleosomes," Nature Communications, vol. 11, no. 1, p. 4136, 2020.

[87] Y. Yoshitomi, T. Ikeda, H. Saito-Takatsuji, and H. Yonekura, "Emerging role of AP-1 transcription factor JunB in angiogenesis and vascular development," International Journal of Molecular Sciences, vol. 22, no. 6, 2021.

[88] H. Chiba, T. Gotoh, T. Kojima et al., "Hepatocyte nuclear factor (HNF) $-4 \alpha$ triggers formation of functional tight junctions and establishment of polarized epithelial morphology in F9 embryonal carcinoma cells," Experimental Cell Research, vol. 286, no. 2, pp. 288-297, 2003.

[89] J.-T. Dong and C. Chen, "Essential role of KLF5 transcription factor in cell proliferation and differentiation and its implications for human diseases," Cellular and Molecular Life Sciences, vol. 66, no. 16, pp. 2691-2706, 2009.

[90] Y. Luo and C. Chen, "The roles and regulation of the KLF5 transcription factor in cancers," Cancer Science, vol. 112, no. 6, pp. 2097-2117, 2021.

[91] S. Shah, M. Pocard, and M. Mirshahi, "Targeting the differentiation of gastric cancer cells (KATO-III) downregulates epithelial-mesenchymal and cancer stem cell markers," Oncology Reports, vol. 42, pp. 670-678, 2019.

[92] M. M. Suzuki and A. Bird, "DNA methylation landscapes: provocative insights from epigenomics," Nature Reviews Genetics, vol. 9, no. 6, pp. 465-476, 2008.
[93] Y. Zhang, C. Liu, H. Cheng et al., "DNA methylation and its effects on gene expression during primary to secondary growth in poplar stems," BMC Genomics, vol. 21, no. 1, p. 498, 2020.

[94] M. Mashhadikhan, H. Kheiri, and A. Dehghanifard, "DNA methylation and gene expression of sFRP2, sFRP4, Dkk 1, and Wif1 during osteoblastic differentiation of bone marrow derived mesenchymal stem cells," Journal of Oral Biosciences, vol. 62, no. 4, pp. 349-356, 2020.

[95] R. Agarwal, Y. Mori, Y. Cheng et al., "Silencing of claudin-11 is associated with increased invasiveness of gastric cancer cells," PLoS One, vol. 4, no. 11, Article ID e8002, 2009.

[96] Z. Zhang, W. Yu, S. Chen, Y. Chen, L. Chen, and S. Zhang, "Methylation of the claudin3 promoter predicts the prognosis of advanced gastric adenocarcinoma," Oncology Reports, vol. 40, pp. 49-60, 2018.

[97] T. Sano, D. G. Coit, H. H. Kim et al., "Proposal of a new stage grouping of gastric cancer for TNM classification: international gastric cancer association staging project," Gastric Cancer, vol. 20, no. 2, pp. 217-225, 2017.

[98] R. Xiang and T. Fu, "Gastrointestinal adenocarcinoma analysis identifies promoter methylation-based cancer subtypes and signatures," Scientific Reports, vol. 10, no. 1, Article ID 21234, 2020.

[99] Y.-C. Ma, J.-Y. Yang, and L.-N. Yan, "Relevant markers of cancer stem cells indicate a poor prognosis in hepatocellular carcinoma patients: a meta-analysis," European Journal of Gastroenterology and Hepatology, vol. 25, no. 9, pp. 10071016, 2013.

[100] H. Xu, Y. Tian, X. Yuan et al., "The role of CD44 in epithelialmesenchymal transition and cancer development," OncoTargets and Therapy, vol. 8, pp. 3783-3792, 2015.

[101] J. Bellmunt, "Stem-like signature predicting disease progression in early stage bladder cancer. The role of E2F3 and SOX4," Biomedicines, vol. 6, 2018.

[102] L. Lu, M. Wu, L. Sun et al., "Clinicopathological and prognostic significance of cancer stem cell markers CD44 and CD133 in patients with gastric cancer: a comprehensive meta-analysis with 4729 patients involved," Medicine, vol. 95, no. 42, Article ID e5163, 2016.

[103] A. Prat, J. S. Parker, O. Karginova et al., "Phenotypic and molecular characterization of the claudin-low intrinsic subtype of breast cancer," Breast Cancer Research, vol. 12, no. 5, p. R68, 2010. 